University of South Florida

DIGITAL COMMONS

Digital Commons @ University of

@ UNIVERSITY OF SOUTH FLORIDA

South Florida

Marine Science Faculty Publications

College of Marine Science

$11-28-2003$

\title{
Interannual Volume Variability in the Tropical Pacific
}

Christina L. Holland

University of South Florida

Gary T. Mitchum

University of South Florida, mitchum@usf.edu

Follow this and additional works at: https://digitalcommons.usf.edu/msc_facpub

Part of the Marine Biology Commons

\section{Scholar Commons Citation}

Holland, Christina L. and Mitchum, Gary T., "Interannual Volume Variability in the Tropical Pacific" (2003). Marine Science Faculty Publications. 50.

https://digitalcommons.usf.edu/msc_facpub/50

This Article is brought to you for free and open access by the College of Marine Science at Digital Commons @ University of South Florida. It has been accepted for inclusion in Marine Science Faculty Publications by an authorized administrator of Digital Commons @ University of South Florida. For more information, please contact digitalcommons@usf.edu. 


\title{
Interannual volume variability in the tropical Pacific
}

\author{
Christina L. Holland and Gary T. Mitchum \\ College of Marine Science, University of South Florida, St. Petersburg, Florida, USA
}

Received 24 February 2003; revised 8 August 2003; accepted 28 August 2003; published 28 November 2003.

[1] The question of whether or not the volume of the tropical Pacific changes over the course of an El Niño event has potentially important consequences for our understanding of the dynamical mechanisms responsible for El Niño-Southern Oscillation (ENSO) events. In this study, we examine the volume variability of the tropical Pacific, defined as the areal integral of the sea surface height variability, using TOPEX/Poseidon altimetric sea surface heights and the output of a numerical model. We find that volume gradually builds up in the tropical Pacific prior to a typical ENSO event and rapidly decreases during the event due to volume flux out of the tropics. However, our results confirm the findings of previous studies showing that volume change over the entire tropical Pacific does occur on ENSO timescales, but that this variability is small when compared to the volume redistribution within the tropical Pacific. In particular, there is a large volume flux into and out of the equatorial waveguide. Furthermore, we find that the volume variability of the tropical Pacific during ENSO can be almost entirely accounted for by variations in the temperature field. INDEX TERMS: 4215 Oceanography: General: Climate and interannual variability (3309); 4522 Oceanography: Physical: El Niño; 4556 Oceanography: Physical: Sea level variations; KEYWORDS: El Niño, interannual variability, sea level, tropical Pacific, volume

Citation: Holland, C. L., and G. T. Mitchum, Interannual volume variability in the tropical Pacific, J. Geophys. Res., 108(C11), 3369, doi:10.1029/2003JC001835, 2003.

\section{Introduction}

[2] Bjerknes [1969] was the first to recognize that the El Niño and the Southern Oscillation phenomena are coupled, and involve a feedback cycle between the atmosphere and the ocean. He pointed out that oceanic warming in the eastern equatorial Pacific would be associated with a decrease in the zonal pressure gradient (typically quantified by the Southern Oscillation Index, or SOI) and a decrease in the intensity of the zonal Walker circulation of the atmosphere. In his view, the sea surface temperature (SST) changes in the eastern tropical Pacific that we refer to as ENSO have far-reaching effects in the atmosphere, which in turn affect the eastern Pacific SST. Once begun, such a scenario is self-sustaining through a positive feedback mechanism. Anomalously warm eastern Pacific sea surface temperatures (SST) lead to a decreased atmospheric zonal pressure gradient, which weakens the winds and decreases the upwelling in the eastern Pacific, thus further increasing the SST. We call the coupled system El Niño-Southern Oscillation (ENSO).

[3] This idea was modified by Wyrtki [1975], who argued that ENSO events are not reliably tied to local changes in the wind stress in the Eastern Pacific. Instead, he suggested, fluctuations in the trade winds of the central equatorial Pacific initiate Kelvin wave pulses, which propagate eastward, carrying warm water and deepening the thermocline in the eastern equatorial Pacific. This deepening of the

Copyright 2003 by the American Geophysical Union. 0148-0227/03/2003JC001835 thermocline then leads to the increased SST. Schopf and Harrison [1983] performed modeling experiments and showed that such Kelvin wave pulses could produce ENSO-like conditions, comparable to observed events, as long as the mean state of the ocean before the event included easterly trade winds and a cold tongue of water extending from the eastern boundary.

[4] This type of description of ENSO soon led to insight into the timescales of the irregular oscillation. Cane and Zebiak [1985] examined the periodicity of events, and determined that the necessary elements for initiating and terminating events were to be found solely within the tropical Pacific. They found that elevated heat content within the equatorial Pacific is a necessary precursor to an El Niño event, so that if the heat content is below or at normal levels, an event will not occur. Cane and Zebiak [1985] argue that this requirement can help explain the temporal irregularity of El Niño events. Zebiak and Cane [1987] produced a coupled atmospheric and oceanic model that exhibited skill in simulating ENSO events, and again found that above normal heat content in the equatorial Pacific was a necessary, but not sufficient, condition for an ENSO event. The latter qualifier means that the heat content value cannot be used as a predictor of events.

[5] Schopf and Suarez [1988], with their delayed oscillator paradigm for ENSO, explicitly tied the temporal spacing of ENSO events to equatorial wave propagation. They argued that the timing is inherent in the system, and they were able to simulate ENSO-like variability in a coupled model with no external time-dependent forcing. The timing, they argued, could be explained by the speeds of oceanic 
wave propagation. The delay between the wind anomalies in the central equatorial Pacific and the SST response in the eastern equatorial Pacific is due to the transit time of eastward propagating, downwelling Kelvin waves. The warm phase of ENSO, which includes positive feedback between the atmosphere and ocean, is then shut down some time later. This lagged shutdown is due to the westward propagating Rossby waves, initiated in the central Pacific at the same time as the faster Kelvin waves. The Rossby waves propagate to the western boundary, and their energy reflects back to the east as upwelling Kelvin waves, undoing the work of the first (downwelling) Kelvin waves. This basic mechanism does not require reflections at the eastern boundary of the basin, and such reflections were found to be unimportant, although we note that Picaut et al. [1996, 1997] later refuted this result. Later, Schopf and Suarez [1990] expanded on these ideas and showed that the westward propagating Rossby wave could be greatly attenuated, down to $20 \%$ of its original amplitude, and the system would still oscillate appropriately. They also found that the zonal extent of the wind anomaly patch was not important, and that increasing the meridional extent led to the generation of higher meridional mode Rossby waves that led to a longer delay time, but not to a change in the amplitude of the oscillation.

[6] These ideas have been extended and refined in a number of studies. For example, Battisti [1989] examined the effect of off-equatorial waves in this picture, and found that they were a result of, not a cause of, the ENSO event. Off-equatorial Rossby waves form when the Kelvin waves reflect from the eastern boundary, but these did not appear to make any contribution to the Kelvin wave which later returned from the western boundary region. Battisti and Hirst [1989] were also able to simulate ENSO-like events using these dynamics, but only if the ocean basin was at least $13,000 \mathrm{~km}$ wide (because wave reflections at the western boundary are critical in the timing). They also found that the basic (i.e., pre-event) state of the system is a crucial factor, which helped to explain why ENSO events are roughly phase-locked to the annual cycle. Neelin [1990] looked at the degree of coupling between the ocean and atmospheric components of coupled models, and found that ENSO events do not occur (the system is stable) in insufficiently coupled systems. As the coupling is increased, the system undergoes a Hopf bifurcation, and ENSO events begin to occur. The amplitude, period, and eastward extent of the events increases as the coupling is further increased until finally, at very high degrees of coupling, the system undergoes another bifurcation and ENSO becomes unstable, which could have implications for the predictability of ENSO.

[7] The delayed oscillator paradigm for ENSO, which makes the role of equatorial wave dynamics paramount, has become generally accepted, and has led to significant progress in predicting ENSO. At the same time, however, evidence suggests that factors outside of the equatorial waveguide may be important in driving and maintaining ENSO events. Recent studies about the role of meridional transports well outside of the waveguide suggest that further progress might be possible, and this motivates the analyses presented here.

[8] In an early study, Wyrtki [1985] used data from a network of tide gauges in the tropical Pacific to estimate the

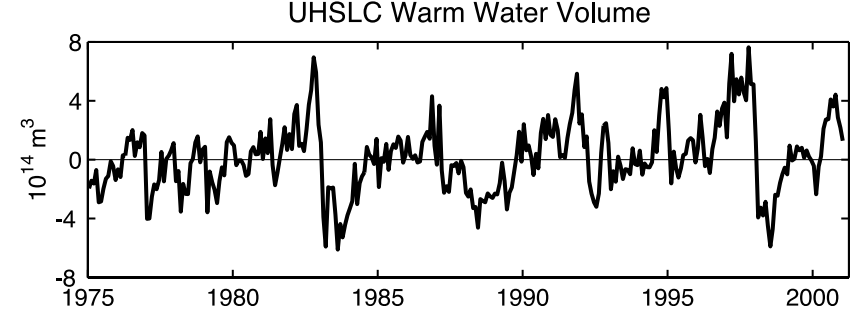

Figure 1. Time series of warm water volume variability between $15^{\circ} \mathrm{S}$ and $15^{\circ} \mathrm{N}$ (after Wyrtki [1985]). This series is computed at the University of Hawaii Sea Level Center (UHSLC) using tropical Pacific tide gauge records. Warm water volume variability is proportional to the areal integral of sea level and is computed via the 1.5-layer assumption with a relative density difference of 0.005 .

variability of what he refers to as the warm water volume of the tropical Pacific. He used the areal integral of sea level variability to estimate this volume variability via a 1.5 -layer approximation for the Pacific basin between $15^{\circ} \mathrm{S}$ and $15^{\circ} \mathrm{N}$, and Figure 1 shows the updated volume time series obtained using his method. He found that the volume tended to build up gradually in the tropical Pacific prior to ENSO warm events, and then was dramatically reduced during the course of the event. From this, he reasoned that ENSO warm events act to "flush" warm water out of the tropical Pacific to higher latitudes. Mitchum [1987] showed evidence that large-scale winds, both zonal and meridional, could be used to form an improved index of ENSO. This is because offequatorial wind anomalies, which were consistent with the Gill atmosphere response [Gill, 1980] to equatorial heating anomalies, can serve to increase convergence of warm water into the equatorial Pacific. This convergence of warm water can feed the eastward Kelvin waves without depleting the warm water of the western Pacific. Later, Perigaud et al. [1997, 2000] also found that off-equatorial wind anomalies could have significant impact on the progression of ENSO. With the Zebiak and Cane [1987] model, ENSO-like behavior could be simulated even in the absence of such off-equatorial wind anomalies, but the resulting simulated oscillations died out within a few years. In the Perigaud et al. [1997, 2000] study, model runs produced sustained interannual variability only when meridional wind stresses were included in the forcing, during both warm and cold phases of ENSO.

[9] This work on the role of off-equatorial variability on ENSO can be seen as laying the groundwork for a modification to the ENSO paradigm, the equatorial ocean recharge theory of $\operatorname{Jin}[1997 \mathrm{a}, 1997 \mathrm{~b}]$. In this view, the thermocline anomaly is set up relatively quickly, as in the delayed oscillator theory. This theory differs from the delayed oscillator theory, though, in the importance of meridional heat transport away from the equator by Rossby waves. This meridional transport leads to negative anomalies in thermocline depth and sea level when these quantities were integrated zonally in the near-equatorial Pacific. A cool anomaly forms along with this anomalously shallow thermocline in the western Pacific. As this anomaly in turn propagates to the east, the eastern Pacific thermocline becomes anomalously shallow and cold water upwells to 
the surface layer, and the warm event thus transitions to the cold phase of the cycle (often referred to as La Niña). Jin's equatorial ocean recharge paradigm is consistent with the delayed oscillator model, but builds upon it. At about the same time, Weisberg and Wang [1997] put forth the western Pacific oscillator model, which further emphasizes the role of off-equatorial SST anomalies in the far western Pacific. This relation between western Pacific variability and ENSO events is further explored by Wang et al. [1999], and further evidence for the west Pacific oscillator's dynamical importance is found by Hasegawa and Hanama [2003], using heat content variability computed from upper ocean temperature observations. Still more recently, Wang [2001] has suggested a unified oscillator model. The physics of the delayed oscillator, the western Pacific oscillator, and other prior ENSO paradigms are included within this unified oscillator model. Different terms dominate at different times, explaining the observed variations from any one event to another. This may provide a useful framework to address the mechanisms behind ENSO, in which ENSO is seen as a combination of many factors, one or more of which may dominate the dynamics for the duration of any particular event, depending on the background conditions.

[10] These alternative views of ENSO are built upon the idea that conditions outside of the equatorial waveguide can have significant impacts on ENSO variability. The underpinning of much of this is the idea of ENSO warm events acting to move warm water out of the tropical Pacific to higher latitudes, an idea first put forward by Wyrtki [1985]. Wyrtki [1985] computed the warm water volume variability over $15^{\circ} \mathrm{S}-15^{\circ} \mathrm{N}$, from the areal integral of sea level variability from tide gauge data. The University of Hawaii Sea Level Center (UHSLC) continues to compute this product, using data up to the present time. Wyrtki's results, however, have been brought into question by more recent studies that use Geosat altimetry [Miller and Cheney, 1990] and numerical model simulations along with tide gauge data [Springer et al., 1990]. Their results indicate that the volume of the tropical Pacific is not affected by ENSO events. Instead, they found that the volume very near the equator decreases during events, but that this is countered by volume increases that are still well within the tropics. This recirculation occurred between the equatorial Pacific, defined as $5^{\circ} \mathrm{S}-5^{\circ} \mathrm{N}$ [Springer et al., 1990] or as $8^{\circ} \mathrm{S}-8^{\circ} \mathrm{N}$ [Miller and Cheney, 1990], and the northern equatorial zone, which extended northward to $20^{\circ} \mathrm{N}$. These results amount to a reinterpretation of the UHSLC volume curve as the volume variability over a near-equatorial $\left(5^{\circ} \mathrm{S}-5^{\circ} \mathrm{N}\right.$ or $8^{\circ} \mathrm{S}-8^{\circ} \mathrm{N}$ ) latitude band, rather than $15^{\circ} \mathrm{S}-15^{\circ} \mathrm{N}$, as it was interpreted by Wyrtki [1985]. Although this is within the tropics, we note that it is still well outside the equatorial waveguide.

[11] Miller and Cheney [1990] used altimetry data from Geosat to reexamine the Wyrtki [1985] volume calculation. Areal integrations of sea level variability computed from satellite altimetry should be more reliable than those computed from tide gauge data, as the spatial resolution is much improved. However, Geosat data was not an ideal indicator of ENSO variability [Wyrtki and Mitchum, 1990]. This is largely due to errors in the water vapor correction, as Geosat, unlike TOPEX/Poseidon, did not have an on-board radiometer [Zimbelman and Busalacchi, 1990]. Of course, the results of Springer et al. [1990], primarily from a numerical model, are similar to those of Miller and Cheney [1990]. We feel, however, that it is appropriate to start by reexamining this question, using both the T/P altimetry and an improved numerical model. From that point, we can proceed to the primary goal of this study: to explore the spatial patterns and dynamics of volume variability in the tropical Pacific during ENSO events.

[12] The above discussion concerns the specific computation of volume described by Wyrtki [1985]. Regardless of the correct interpretation of this computation, the underlying question is still relevant and interesting. Does the volume of the tropical Pacific, as a whole, vary over the course of an El Niño event? This has implications for our understanding of the fundamental dynamics of ENSO, in light of the equatorial ocean recharge paradigm of Jin [1997a, 1997b]. We will address this question using both $\mathrm{T} / \mathrm{P}$ data and numerical model results. We are also interested in what happens within the tropical Pacific. Miller and Cheney [1990] and Springer et al. [1990] found that the majority of the near-equatorial volume change during ENSO is recirculated within the tropics. How does this redistribution occur? What are the spatial patterns (zonal and meridional) associated with the redistribution? What are the dominant dynamics?

[13] We should also ask, of course, what are the underlying mass and heat transport pathways that give rise to the observed volume variations of the tropical Pacific. That question will be addressed in a later paper. This paper is organized as follows. Section 2 describes the data used, including the TOPEX/Poseidon altimetric sea surface height data and the output of a numerical model, and the analysis methods employed. This includes a precise definition of what is meant by volume, and a careful identification of the dynamics that can alter this volume. Section 3 presents our results for a series of geographic regions. Section 3.1 concerns the dynamics of volume variability of the tropical Pacific as a whole, section 3.2 addresses meridional redistributions, section 3.3 simultaneously addresses meridional and zonal redistribution patterns, and section 3.4 explores the robustness of the results based on the numerical model. The major conclusions are discussed and summarized in section 4 .

\section{Data and Methods}

[14] To begin with, we will address the results of Wyrtki [1985] and their later reinterpretation by Miller and Cheney [1990] and Springer et al. [1990]. That study integrated sea level from a network of tide gauge stations in the Pacific between $15^{\circ} \mathrm{S}$ and $15^{\circ} \mathrm{N}$ to form an estimate of tropical Pacific water volume. We will reexamine the UHSLC volume curve using TOPEX/Poseidon (T/P) altimetry data. To facilitate integration of the altimetry over geographic areas, we use a $1^{\circ}$ gridded $\mathrm{T} / \mathrm{P}$ product.

[15] The questions posed by this study require the availability of three-dimensional and time-varying fields of velocity, temperature, and salinity. There are many types of data available for the tropical Pacific, each of which meets some of the requirements. Satellite data provide excellent horizontal coverage, but only at the sea surface, and only for a few years or 1 decade. Tide gauge records often have longer records, but are again only a measure of surface 
properties and are sparse horizontally. Vertical profile data is plentiful in the tropical Pacific due to the TOGA-TAO and TOGA-COARE programs, but this again provides information at only specific horizontal points. For this reason, the current study primarily uses a numerical model based on the Gent and Cane [1989] sigma-coordinate model, although the model we use has been modified extensively. In its present configuration, it is coupled to an atmospheric mixed layer model [Murtugudde and Busalacchi, 1998; Seager and Murtugudde, 1995], and includes the effects of salinity and freshwater flux [Murtugudde et al., 1996]. Vertical mixing is dealt with via the hybrid mixing scheme of Chen et al. [1994] that simulates the wind stirring, shear instability, and convective overturning mechanisms of vertical turbulent mixing. This model is a sigma-coordinate model. There are 20 active layers in the vertical, with a 21 st layer assumed to be infinitely deep, homogenous, and completely at rest. The thickness of the mixed layer and the total thickness of the remaining active layers are determined by the computation of horizontal divergences, and the individual thicknesses of vertical layers 2 through 20 are determined by separating the total active layer thickness into layers that have constant relative thicknesses. The vertical velocities between the layers are determined by continuity. Temperature and salinity are computed in each layer from surface forcing, vertical mixing, and horizontal transports, and the horizontal velocities are computed from the momentum equation. Dissipation is accomplished through a Shapiro [1970] horizontal filter.

[16] What we refer to as volume in this study should be interpreted as total volume over the water column. Assuming that the seafloor is unchanging over the timescales we are interested in, the volume variability is simply the variability in sea level, integrated horizontally over some region of interest. Alternatively, one could define volume as the areal integral of the total thickness of the active layers in the model that we employ. However, the temperature and salinity within each layer are variable functions both of horizontal location and of time, so such a measure of volume would not have a clear and simple physical interpretation. One could also attempt to compute volume as the areal integral of the thickness of water above some isothermal or isobaric surface. This thickness, however, cannot easily be resolved in this model, as temperature and density are vertically constant within each layer and layers are typically tens of meters thick. The interpretation of volume variability that we use here, the areal integration of sea level variability, is analogous to the warm water volume variability used by other studies [Wyrtki, 1985; Miller and Cheney, 1990; Springer et al., 1990]. If one assumes a 1.5-layer ocean, then our volume variability can be converted to the warm water volume variability, which is the volume of water above the thermocline, by multiplying by the relative density difference between the warm and cold layers.

[17] In the model, the sea level is a diagnostic variable that is computed from the vertical integral of the buoyancy, which is inversely related to the density. The equation of state in the model, which determines the density and hence the buoyancy, is a fourth-order nonlinear equation of temperature and salinity, and using this equation would make it nearly impossible to separate the volume changes due to heat, salt, and mass content. We therefore first asked whether a linearized equation of state was a reasonable approximation. To check this, volume time series for the region $20^{\circ} \mathrm{S}-20^{\circ} \mathrm{N}$ in the Pacific were computed using both the full model equation of state and a linear equation of state with the coefficients selected by least squares. These two time series were correlated to 0.99 , and the volume series from the linearized equation of state accounts for $94 \%$ of the variance of the volume series from the full equation. This variance percentage is increased to $96 \%$ if the mean seasonal cycle is first removed from both time series. From this point forward, therefore, sea level is computed from

$$
\eta=b H+\alpha \int_{-H}^{0} \mathrm{Tdz}+\beta \int_{-\mathrm{H}}^{0} \mathrm{Sdz}
$$

where $\mathrm{H}$ is the bottom interface depth of the lowest active layer. The coefficients of heat and salt content are $\alpha=$ $0.25 \times 10^{-3} \mathrm{~K}^{-1}$ and $\beta=-0.76 \times 10^{-3} \mathrm{psu}^{-1}$. The temperatures and salinities have been referenced to their values in the lowest (inactive) model layer, which are $\mathrm{T}_{\text {ref }}=$ $6 \mathrm{~K}$ and $\mathrm{S}_{\mathrm{ref}}=35 \mathrm{psu}$, and the $\mathrm{b}$ coefficient is computed from

$$
\mathrm{b}=\mathrm{b}_{0}+\alpha \mathrm{T}_{\text {ref }}+\beta \mathrm{S}_{\mathrm{ref}},
$$

with $\mathrm{b}_{0}=25 \times 10^{-3}$.

[18] The model enforces conservation of mass (the continuity equation), heat, salt, and momentum. The vertically integrated forms of the conservation equations for mass, heat, and salt are of primary interest here, and these are written

$$
\begin{gathered}
\frac{\partial \mathrm{H}}{\partial \mathrm{t}}=-\nabla \cdot \widetilde{\mathrm{U}} \\
\frac{\partial \Theta}{\partial \mathrm{t}}=-\nabla \cdot \widetilde{\theta}+\frac{1}{\rho_{0} \mathrm{c}_{\mathrm{p}}} \mathrm{Q}, \\
\frac{\partial \Gamma}{\partial \mathrm{t}}=-\nabla \cdot \widetilde{\gamma}+\mathrm{S}_{0}(\mathrm{E}-\mathrm{P}),
\end{gathered}
$$

where

$$
\Theta=\int_{-H}^{0} \mathrm{~T} d z
$$

is the heat content of the active model layers, and

$$
\Gamma=\int_{-\mathrm{H}}^{0} \mathrm{~S} \mathrm{dz}
$$

is the salt content of the active model layers. $\tilde{\mathrm{U}}, \widetilde{\theta}$, and $\widetilde{\gamma}$ are the horizontal transports of mass, heat, and salt, defined as

$$
\widetilde{U}=\int_{-H}^{0} \tilde{u} d z
$$




$$
\begin{aligned}
& \widetilde{\theta}=\int_{-H}^{0} \widetilde{\mathrm{u}} \mathrm{Tdz}, \\
& \widetilde{\gamma}=\int_{-H}^{0} \widetilde{\mathrm{u} S ~ d z}
\end{aligned}
$$

and $\mathrm{H}$ is again the total thickness of the active layers. $\mathrm{Q}$ is the heat flux at the sea surface, $\mathrm{S}_{0}$ is the sea surface salinity, and E-P is evaporation minus precipitation. These balances are enforced every time step, but the resulting model fields are output only once a month (every 720 model time steps). At each horizontal point, the conservation equations (3) cannot be used to exactly compute changes in mass, heat, or salt content over a month from the horizontal transport divergences and sea surface fluxes taken at a single discrete time step. Instead, monthly averages of all flux quantities present in such balance equations were computed and output from the model. Even with monthly integrals of the flux quantities, however, the balances are still not exact, because of the effect of the Shapiro horizontal filter. This effect is generally small, but in some areas the fluxes of mass, heat, and salt are nearly horizontally non-divergent. The total horizontal divergences, which determine the time evolution of the system according to equations (3), are then small values resulting from the nearly exact cancellation of the large zonal and meridional divergences. After the application of the Shapiro filter, the zonal and meridional components of the flux divergences no longer balance as closely. This leads to mismatches between the right-hand side of equations (3), which is computed from the divergences, and the temporal evolution on the left-hand side. For the purposes of the present study, this effect is simply noted and quantified. It occurs primarily in the western boundary region and near the equator, where the horizontal flows are the strongest.

[19] As discussed above, volume changes are determined from the areal integral of the sea surface height deviations. We form a diagnostic equation for the volume rate of change over any geographic region by doing an areal integration of the time derivative of equation (1) and substituting flux terms for time derivatives using equations (3). The resulting equation is

$$
\begin{aligned}
\frac{\partial \mathrm{V}}{\partial \mathrm{t}}= & \mathrm{b} \iint \frac{\partial \mathrm{H}}{\partial \mathrm{t}} \mathrm{dA}+\alpha \iint \frac{\partial \Theta}{\partial \mathrm{t}} \mathrm{dA}+\beta \iint \frac{\partial \Gamma}{\partial \mathrm{t}} \mathrm{dA} \\
= & \mathrm{b}\left[-\mathrm{V}_{\mathrm{N}}+\mathrm{V}_{\mathrm{S}}-\mathrm{U}_{\mathrm{E}}+\mathrm{U}_{\mathrm{W}}-\iint \mathrm{D}_{\mathrm{H}} \mathrm{dA}\right] \\
& +\alpha\left[-\theta_{\mathrm{N}}+\theta_{\mathrm{S}}-\theta_{\mathrm{E}}+\theta_{\mathrm{W}}+\frac{1}{\rho_{0} \mathrm{c}_{\mathrm{p}}} \iint \mathrm{Q} \mathrm{dA}-\iint \mathrm{D}_{\Theta} \mathrm{dA}\right] \\
& +\beta\left[-\gamma_{\mathrm{N}}+\gamma_{\mathrm{S}}-\gamma_{\mathrm{E}}+\gamma_{\mathrm{W}}+\iint \mathrm{S}_{0}(\mathrm{E}-\mathrm{P}) \mathrm{dA}\right. \\
& \left.-\iint \mathrm{D}_{\Gamma} \mathrm{dA}\right]
\end{aligned}
$$

where $\mathrm{V}$ is the volume of the box, the subscripted $\mathrm{U}$ and $\mathrm{V}$ terms are the vertically integrated zonal and meridional mass transports, $\theta$ is the horizontal heat transport, $\gamma$ is the horizontal salt transport, the subscripts $\mathrm{N}, \mathrm{S}, \mathrm{E}$, and $\mathrm{W}$ reference fluxes across the northern, southern, eastern, and western faces of the geographic box, respectively, and the areal integral of $\mathrm{D}$ terms are the mismatches in the continuity, heat, and salt balances due to the application of the Shapiro filter.

[20] The model is spun up for 20 years using climatological fields of wind stress, sea surface radiation, precipitation, and cloud cover. After spin up, the model was run for 43 years. In this study, we are interested in the interannual variability associated with the ENSO events during this time period. Rather than comparing one event to another, however, we will focus on a composite event. The inter-event variability is interesting, but our aim here is focus on features common to all events. To isolate the typical interannual signal, an ENSO composite is formed from every time series, using the SOI as a guide. We isolated interannual variability in the SOI by removing a 41-month median filter from the SOI time series, and then computing an 11-month median filter of the residual. This method preserves $74 \%$ of the variance in the $2-7$ year ENSO band, while reducing the variance on timescales longer than 7 years or shorter than 2 years to $21 \%$ and $25 \%$, respectively. This filtering was done only on the SOI, to highlight important El Niño events. The volume time series were not filtered in this manner. Four large El Niño events, the 1972/ $1973,1982 / 1983,1986 / 1987$, and 1997/1998 events, have a magnitude exceeding 1.5 times the standard deviation. The ENSO composite of any time series is computed by averaging four sections of the time series, 6 years in length and centered on the month with the minimum SOI corresponding to the four events listed above. Examples for the volume tendency and volume time series over several geographic boxes are shown in Figure 2. Over a typical ENSO cycle from 1 year prior to the peak warming until 1 year after the peak (as marked by the dots on Figure 2) the volume decreases over $20^{\circ} \mathrm{S}-20^{\circ} \mathrm{N}$. This can further be divided into a volume decrease over $5^{\circ} \mathrm{S}-8^{\circ} \mathrm{N}$ and $20^{\circ} \mathrm{S}-5^{\circ} \mathrm{S}$, and a volume increase during the same time period over $8^{\circ} \mathrm{N}-20^{\circ} \mathrm{N}$.

[21] The importance of each term in equation (7), the equation for the volume tendency, must be evaluated for each geographic region. In this paper, we deal only with the effect of each term on the composite ENSO event. We wanted to reduce the composite time series of each term to a single numerical value, and we employed two methods for doing this. For convenience in presenting these two methods, we first write the volume equation schematically as

$$
\frac{\partial \mathrm{V}}{\partial \mathrm{t}}=\sum_{\mathrm{n}=1}^{17} \frac{\partial \mathrm{V}_{\mathrm{n}}}{\partial \mathrm{t}}
$$

where the 17 terms in the summation are from the righthand side of equation (7). The first method for computing indices was to compute the covariance of each term with an SOI probe,

$$
\lambda_{\mathrm{n}}^{(1)}=100 \% \times\left[\operatorname{cov}\left(\frac{\partial \mathrm{V}_{\mathrm{n}}}{\partial \mathrm{t}}, \mathrm{SOI}\right) / \operatorname{cov}\left(\frac{\partial \mathrm{V}}{\partial \mathrm{t}}, \mathrm{SOI}\right)\right],
$$




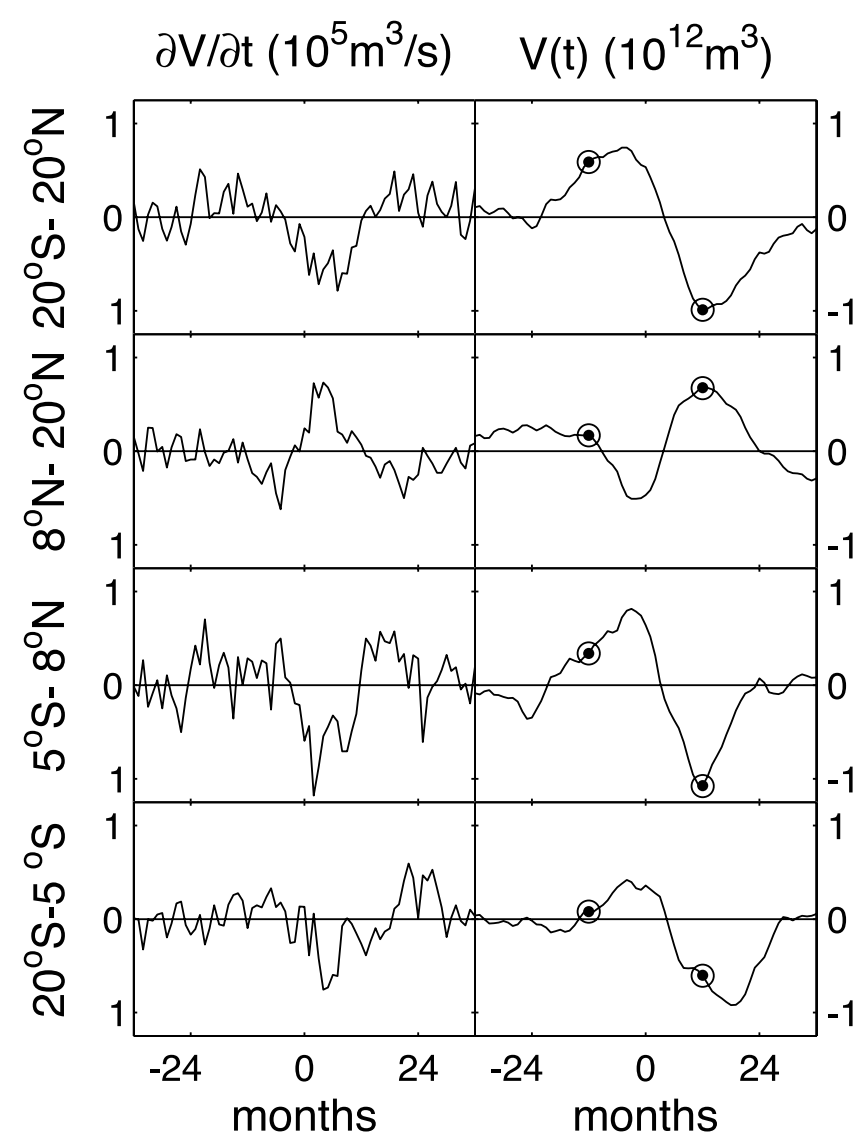

Figure 2. Composite time series of volume tendency (lefthand panels) and volume variability (right-hand panels). These curves are from an areal integration over latitude ranges indicated on the figure and from the eastern to western zonal boundaries. The circles in the right-hand panels indicate the volume within each box 12 months before and after the peak of ENSO warming. The volume decreases over this 2-year period in the tropical Pacific $\left(20^{\circ} \mathrm{S}-20^{\circ} \mathrm{N}\right)$, equatorial $\left(5^{\circ} \mathrm{S}-8^{\circ} \mathrm{N}\right)$, and southern equatorial $\left(20^{\circ} \mathrm{S}-5^{\circ} \mathrm{S}\right)$ boxes and increases over the same time interval in the northern $\left(8^{\circ} \mathrm{N}-20^{\circ} \mathrm{N}\right)$ box.

where SOI is the composite SOI time series. Alternatively, each time series was integrated over a 2-year period centered on the peak of the ENSO event,

$$
\lambda_{\mathrm{n}}^{(2)}=100 \% \times\left[\int_{-\tau}^{\tau} \frac{\partial \mathrm{V}_{\mathrm{n}}}{\partial \mathrm{t}} \mathrm{dt} / \int_{-\tau}^{\tau} \frac{\partial \mathrm{V}}{\partial \mathrm{t}} \mathrm{dt}\right],
$$

where $\tau=1$ year. These indices are dimensionless and serve to determine the relative importance of each term in changing the volume of a geographic box. That is, a large value for a given $\lambda_{n}$ indicates that the associated flux term in equation (7) is important in the volume tendency at that location and allows us to attribute the volume changes to specific processes. These methods gave very similar results, and the results given in the next section are from the first method.

\section{Results}

\subsection{Tropical Pacific Volume Variability}

[22] The UHSLC volume curve (Figure 1) has usually been interpreted as the volume variability over the latitude range $15^{\circ} \mathrm{S}-15^{\circ} \mathrm{N}$, and shows a clear steady build-up in volume prior to ENSO events and a sharp decrease during the events [Wyrtki, 1985]. This conflicts with the evidence of other studies, including Miller and Cheney [1990], who found that volume is lost from a narrow zone around the equator $\left(8^{\circ} \mathrm{S}-8^{\circ} \mathrm{N}\right)$ but is recirculated within the tropics, with a volume gain between approximately $8^{\circ} \mathrm{N}$ and $20^{\circ} \mathrm{N}$ that cancels out the near-equatorial loss. The findings of Springer et al. [1990] were similar to those of Miller and Cheney [1990], but defined the near-equatorial band of volume loss differently, as $5^{\circ} \mathrm{S}-5^{\circ} \mathrm{N}$. These studies found that the UHSLC $15^{\circ} \mathrm{S}-15^{\circ} \mathrm{N}$ volume curve is more correctly interpreted as the volume over a smaller, near-equatorial volume range. We begin by reevaluating this question using the $\mathrm{T} / \mathrm{P}$ altimetry data.

[23] The top panel of Figure 3 shows the UHSLC volume compared to the T/P altimetry integrated over the Pacific from $15^{\circ} \mathrm{S}-15^{\circ} \mathrm{N}$. The agreement is less than satisfactory, with a correlation of only 0.5 . The UHSLC volume curve is predominately interannual in character, while the integrated $\mathrm{T} / \mathrm{P}$ volume has a larger annual cycle. The UHSLC volume curve actually agrees much more closely with the T/P altimetry integrated over the Pacific between $6^{\circ} \mathrm{S}$ and $6^{\circ} \mathrm{N}$, as shown in the bottom panel of Figure 3. The correlation between these time series is 0.8 . In fact, we integrated the T/P altimetry over latitude ranges of varying width about the equator. The correlation increases with smaller and smaller bands about the equator for $T / P$, suggesting that the UHSLC volume variability is dominated by near-equatorial variability. The standard deviation of the difference between the UHSLC and integrated $\mathrm{T} / \mathrm{P}$ volumes is at a minimum for the range $6^{\circ} \mathrm{S}-6^{\circ} \mathrm{N}$. We confirm the

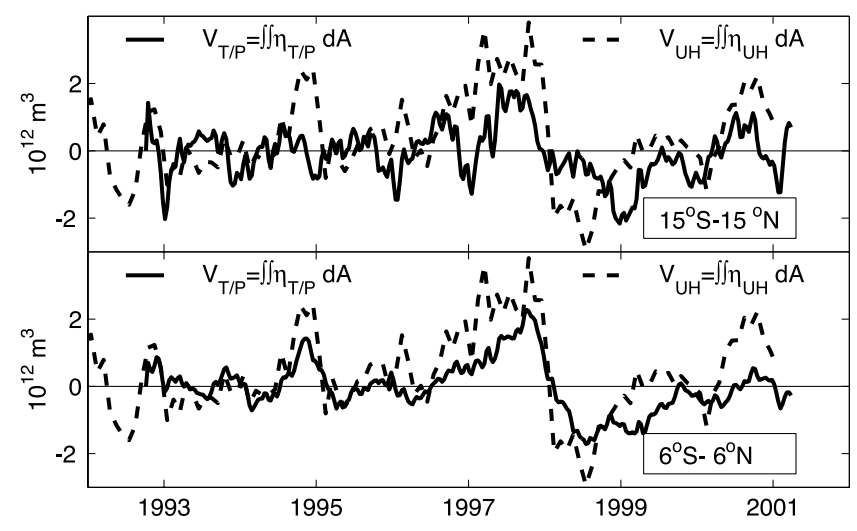

Figure 3. Time series of volume variability from $\mathrm{T} / \mathrm{P}$ sea surface heights $(\mathrm{SSH})$ as compared to the volume (areal integral of sea level, not warm water volume) from the UHSLC. In the top panel, the solid line is the volume computed from the integral of $\mathrm{T} / \mathrm{P} \mathrm{SSH}$ over the range $15^{\circ} \mathrm{S}-15^{\circ} \mathrm{N}$. In the bottom panel, the solid line is the same, but for the range $6^{\circ} \mathrm{S}-6^{\circ} \mathrm{N}$. The dashed line in each is the UHSLC volume. Correlation between the UHSLC volume and the T/P volume increases as the latitude range for the T/P volume in decreased, until it reaches and maintains its maximum value, 0.8 , for latitude ranges extending between $4^{\circ}$ and $8^{\circ}$ away from the equator. The standard deviation of the difference is minimum when a latitude range of $5^{\circ} \mathrm{S}-5^{\circ} \mathrm{N}$ or $6^{\circ} \mathrm{S}-6^{\circ} \mathrm{N}$ is used to compute the T/P volume. 


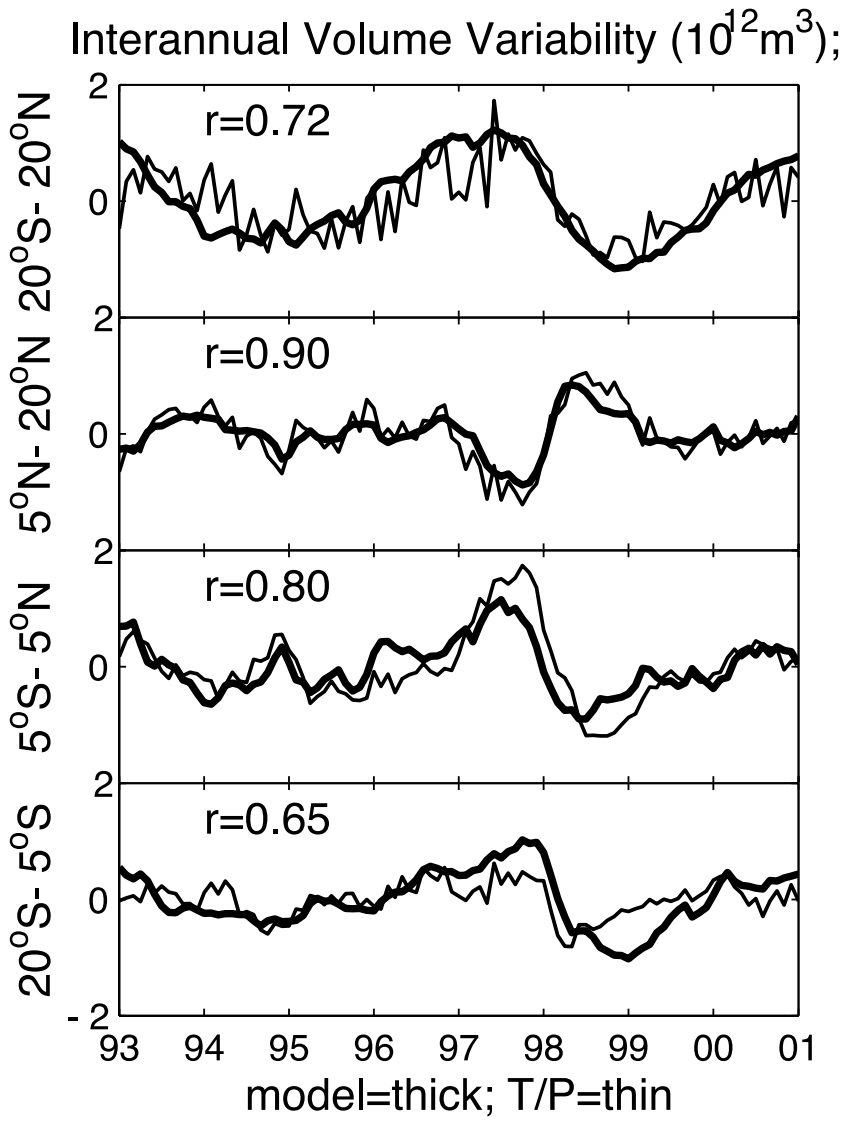

Figure 4. Time series of water volume variability for different latitude bands in the Pacific. The thick lines in every panel are computed from the numerical model, and the thin lines are computed from T/P altimetry. The longterm mean, the trend, and the mean annual cycle have been removed to show the interannual variability. The top panel is for the latitude range $20^{\circ} \mathrm{S}-20^{\circ} \mathrm{N}$, the second panel is for $5^{\circ} \mathrm{N}-20^{\circ} \mathrm{N}$, the third panel is for $5^{\circ} \mathrm{S}-5^{\circ} \mathrm{N}$, and the bottom panel is for $20^{\circ} \mathrm{S}-5^{\circ} \mathrm{S}$.

findings of Miller and Cheney [1990] and Springer et al. [1990] that the UHSLC time series is better interpreted as the volume variability over the near-equatorial Pacific, and suggest that the correct latitude range is approximately $6^{\circ} \mathrm{S}-6^{\circ} \mathrm{N}$.

[24] The T/P heights are also useful for evaluating the model results that we will primarily be using to examine the dynamics of the volume variability in the tropical Pacific. If we can establish that the model volume changes are consistent with the $\mathrm{T} / \mathrm{P}$ changes for the time period when we have the T/P data, then we will have more confidence in diagnosing the way in which the model accomplishes the volume variations. To do this, the volume over a variety of latitude ranges was compared between the model and the areal integral of the $\mathrm{T} / \mathrm{P}$ altimetry, and the results were encouraging. The time series are shown in Figure 4. They have comparable levels of variance, and the interannual portions are correlated at 0.72 for the $20^{\circ} \mathrm{S}-20^{\circ} \mathrm{N}$ box, 0.90 for the $5^{\circ} \mathrm{N}-20^{\circ} \mathrm{N}$ box, and 0.80 for the $5^{\circ} \mathrm{S}-5^{\circ} \mathrm{N}$ box. The correlation is lower $(0.65)$ for the $20^{\circ} \mathrm{S}-5^{\circ} \mathrm{S}$ box, but that is not surprising, as the interannual variability in that box is low for both the model and the $\mathrm{T} / \mathrm{P}$ altimetry. Both the model and the T/P altimetry show a gradual build-up of volume in the $20^{\circ} \mathrm{S}-20^{\circ} \mathrm{N}$ box prior to the $1997 \mathrm{El}$ Niño event as well as a rapid volume decrease of approximately $10^{12} \mathrm{~m}^{3}$ during the event. We find that although the calculation described by Wyrtki [1985] does not truly reflect the volume variability over the entire tropical Pacific, nevertheless the central idea of that paper appears to be correct. On the basis of T/P altimetry data during the 1997 El Niño event, the tropical Pacific as a whole does gradually increase in volume prior to El Niño events, and this is countered by a sharp decrease in volume during the event.

[25] In addition, empirical orthogonal functions (EOFs) were computed from the zonally integrated sea level in both $\mathrm{T} / \mathrm{P}$ and the model to gauge whether the meridional redistribution patterns were comparable. In each, the first two modes accounted for approximately $75 \%$ of the variance and captured the interannual and seasonal variability, respectively, with comparable meridional patterns. The first (interannual) mode, which accounts for over half of the variance in both $\mathrm{T} / \mathrm{P}$ and model, has a change in sign north of the equator, at $5^{\circ} \mathrm{N}$ for $\mathrm{T} / \mathrm{P}$ and at $8^{\circ} \mathrm{N}$ for the model, indicating that interannual volume loss in the near-equatorial and southern tropics is at least partially compensated for by volume gain north of this transition latitude. The correlation between model and T/P is 0.80 temporally and 0.82 meridionally for this mode. The analogous correlations for the second mode, which captures the seasonal variability, are 0.62 temporally and 0.74 meridionally.

[26] The first question we will address is, how does the volume of the tropical Pacific as a whole vary over an ENSO warm event? We do see a sharp drop in volume over $15^{\circ} \mathrm{S}-15^{\circ} \mathrm{N}$ in the T/P altimetry data (Figure 3) for the 1997 strong ENSO warm event, although it is small when compared to the volume drop from the near-equatorial region. It is natural to use the numerical model to address this, as we can not only examine volume variability within any geographic box, we can also assess the importance of mass, heat, and salt fluxes from one box to another from equations (6), (9), and (10). We will start with the tropical Pacific as a whole, and later we divide this into a series of smaller geographic regions.

[27] We start by defining the tropical Pacific as extending from $20^{\circ} \mathrm{S}$ to $20^{\circ} \mathrm{N}$. The interannual volume variability over this latitude range from the Gent and Cane [1989] model is shown in Figure 5. The volume drops during El Niño events range between 1.5 and $3 \times 10^{12} \mathrm{~m}^{3}$, which corresponds to a drop in the areally averaged sea level of between 2 and $4 \mathrm{~cm}$, comparable to the results of Springer et al. [1990] for the entire tropical Pacific, as evidenced by Figure 3 of their paper. The time series shown here have been filtered to isolate the interannual signal in the following fashion. First, a low-frequency function, consisting of the mean, trend, quadratic, and an exponential term was fitted and removed. Then the mean annual cycle was removed from the residual. We know from equation (7) that the volume variability can result from changes in mass, heat, or salt content in the active layers of the model. We also know that there are certain error or mismatch terms in each of these balances, which result from the horizontal filtering applied within the model for stability. In Figure 5, we have separated out the 


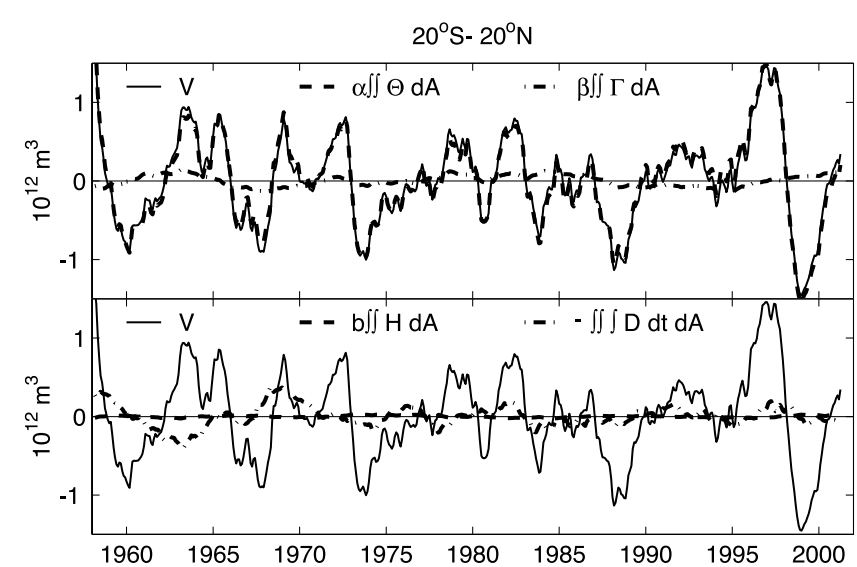

Figure 5. Time series of the model volume variability and its constituents for the $20^{\circ} \mathrm{S}-20^{\circ} \mathrm{N}$ box. The solid line in both panels is the volume variability time series. The dashed line in the top panel, nearly overlying the volume, is the portion of the volume variability that is due to temperature variability. The dash-dotted line on the top panel is the volume variability due to salinity changes. In the bottom panel, the dashed and dash-dotted lines are the volume variability due to continuity effects (changes in mass within the area) and mismatches from model filtering, respectively.

error terms and grouped them together. The contributions shown, then, are

$\mathrm{V}=\mathrm{b} \iint \mathrm{HdA}+\alpha \iint \Theta \mathrm{dA}+\beta \iint \Gamma \mathrm{dA}-\iiint \mathrm{D} \mathrm{dt} \mathrm{dA}$,

where

$$
\mathrm{b} \iint \mathrm{H} d A=b \int\left(-\mathrm{V}_{\mathrm{N}}+\mathrm{V}_{\mathrm{S}}-\mathrm{U}_{\mathrm{E}}+\mathrm{U}_{\mathrm{W}}\right) \mathrm{dt}
$$

is the mass content contribution to the volume variability,

$$
\alpha \iint \Theta \mathrm{dA}=\alpha \int\left(-\theta_{\mathrm{N}}+\theta_{\mathrm{S}}-\theta_{\mathrm{E}}+\theta_{\mathrm{W}}+\frac{1}{\rho_{0} \mathrm{c}_{\mathrm{p}}} \iint \mathrm{Q} \mathrm{dA}\right) \mathrm{dt}
$$

is the heat content contribution to the volume variability,

$\beta \iint \Gamma \mathrm{dA}=\beta \int\left(-\gamma_{\mathrm{N}}+\gamma_{\mathrm{S}}-\gamma_{\mathrm{E}}+\gamma_{\mathrm{W}}+\iint \mathrm{S}_{0}(\mathrm{E}-\mathrm{P}) \mathrm{dA}\right) \mathrm{dt}$

is the salt content contribution to the volume variability, and

$$
\begin{aligned}
\iiint \mathrm{D} d \mathrm{dt} \mathrm{dA}= & \mathrm{b} \iiint \mathrm{D}_{\mathrm{H}} \mathrm{dt} \mathrm{dA}+\alpha \iiint \mathrm{D}_{\Theta} \mathrm{dt} \mathrm{dA} \\
& +\beta \iiint \mathrm{D}_{\Gamma} \mathrm{dt} \mathrm{dA}
\end{aligned}
$$

is the error term. It is clear from Figure 5 that the heat content variability (equation (13)) is responsible for the majority of the volume variability over the tropical Pacific from $20^{\circ} \mathrm{S}-20^{\circ} \mathrm{N}$. The contributions from salt and mass content are actually less than the error term. The heat content variability is correlated to the volume variability to 0.99 and accounts for $99.2 \%$ of its variance.

[28] The importance of horizontal fluxes of mass, heat, and salt at the northern and southern faces of the $20^{\circ} \mathrm{S}-$ $20^{\circ} \mathrm{N}$ box and of the sea surface heat and freshwater fluxes were evaluated using equation (7) to define the contributing terms, forming composites of all the time series, and using equations (9) and (10) to compute scalar indices for each. Those resulting from equation (9) are shown in schematic form in Figure 6. The volume of this box drops during ENSO events, and the numbers shown are percentages of this drop. For example, the outgoing heat flux at the sea surface (cooling of the ocean) accounts for $65 \%$ of the total drop in volume over the box. The other dominant term is the northward heat flux at the $20^{\circ} \mathrm{N}$ face, which accounts for $22 \%$ of the total volume loss. Only terms that contribute more than $0.5 \%$ to the volume change are included here. The continuity (mass flux) terms are smaller than this cutoff and are not shown. The heat flux terms dominate, just as the heat flux variability dominates the volume variability (Figure 5), and the salt flux terms are typically $20 \%$ of their
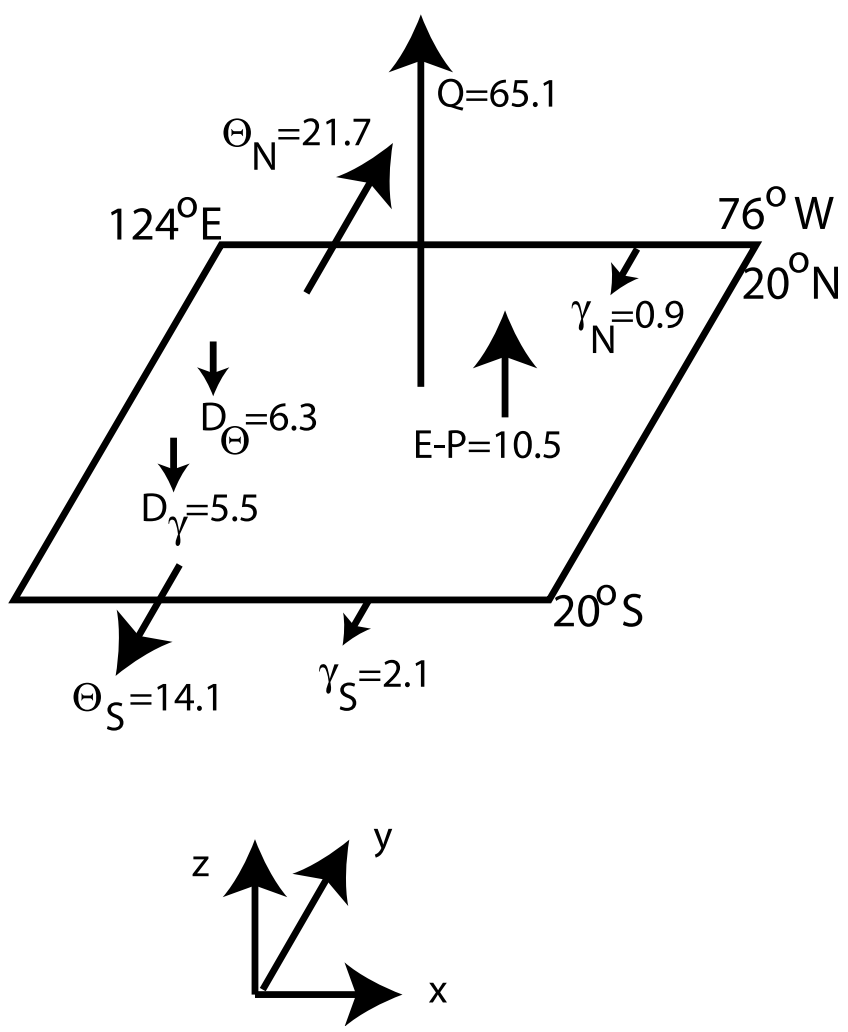

Figure 6. Schematic of volume tendency effects for the $20^{\circ} \mathrm{S}-20^{\circ} \mathrm{N}$ box. The region is shown as an inclined plane. The effects shown are the heat flux at the sea surface, Q; the freshwater flux at the sea surface, E-P; heat fluxes across the northern and southern faces, $\theta_{\mathrm{N}}$ and $\theta_{\mathrm{S}}$; salt fluxes across the northern and southern faces, $\gamma_{\mathrm{N}}$ and $\gamma_{\mathrm{S}}$; and mismatches in the temperature and salinity equations, $\mathrm{D}_{\Theta}$ and $\mathrm{D}_{\Gamma}$. Only terms larger than $0.5 \%$ of the total $20^{\circ} \mathrm{S}-20^{\circ} \mathrm{N}$ volume change are included in the schematic. The number next to the arrow indicates the relative importance of each term. 
corresponding heat flux terms, or even smaller. The eastern and western faces of the box are coastlines, so there are no fluxes across these faces.

[29] We therefore conclude that the heat content variability in the model dominates the volume variability over $20^{\circ} \mathrm{S}-20^{\circ} \mathrm{N}$. Further, we have found that there is a characteristic drop in volume over this latitude range during ENSO events, although we will later show that it is much less than the volume lost from a narrower latitude band about the equator. The dominant factors in this volume loss are the upward heat flux at the sea surface and the poleward heat fluxes at $20^{\circ} \mathrm{N}$ and $20^{\circ} \mathrm{S}$, as shown in Figure 6 . There are other ways of approaching this same problem. J. M. Toole et al. (On the time-dependent internal energy budgets of the tropical warm water pools, submitted to Journal of Climate, 2002) (hereinafter referred to as Toole et al., submitted manuscript, 2002) also found interannual variability in the amount of warm pool water, but with the decrease beginning at the time of minimum SOI. These authors note that this is different than the results of Wyrtki [1985] and Meinen and McPhaden [2000], although the reason for the phase difference was not clear. The results we present here are consistent with those earlier studies. We note that our methods were quite different than those of Toole et al. (submitted manuscript, 2002). Those authors were concerned with the evolution of the mass of Indo-Pacific water warmer than $28^{\circ} \mathrm{C}$, which is rather different from the volume of water between specified latitude bands.

\subsection{Meridional Redistribution}

[30] As discussed earlier, previous studies [Miller and Cheney, 1990; Springer et al., 1990] have argued that volume lost from the near-equatorial region is largely balanced by gain elsewhere within the tropics, particularly in the northern tropical Pacific. This is in contrast to the suggestion by Wyrtki [1985] that the tropics as a whole experience volume loss. Our results to this point indicate that the volume of the tropics does decrease sharply during events, but we have only examined the tropics as a whole. We will now discuss the redistribution of volume within the tropical Pacific, again using the output of the numerical model.

[31] To begin with we will look only at meridional redistribution by zonally integrating the model sea level. As previously noted, this method produced similar results for both the numerical model and the T/P altimetry. Now we apply the same technique to the entire model record, which begins in 1958. Taking the zonal integral of sea level, a function of longitude, latitude, and time, results in a function of only latitude and time. The first EOF mode of this function accounts for more than half of the variance and is significant at the $95 \%$ level. The time series associated with this first mode is shown in the top panel of Figure 7 , and we see that it captures the interannual signal of slow build-up prior to ENSO events and sharp drops during events. The interannual composite of the derivative of this time series is similar to the SOI, with a correlation of 0.57 . The meridional pattern of this mode (not shown) has one change of sign, at $8^{\circ} \mathrm{N}$, and a local minimum at $5^{\circ} \mathrm{S}$. The lower panel of Figure 7 shows the covariance of the model sea level at every horizontal grid point with the first mode time series, and the $5^{\circ} \mathrm{S}$ and $8^{\circ} \mathrm{N}$ lines clearly divide distinct

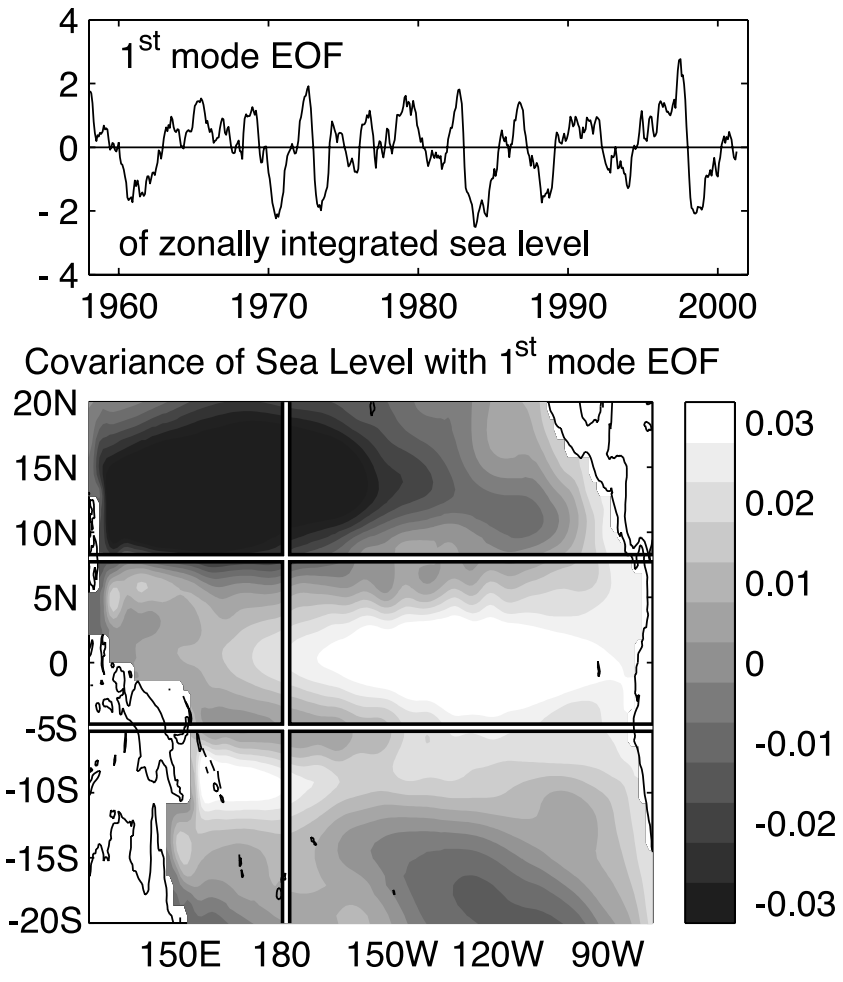

Figure 7. First empirical orthogonal function (EOF) mode of the zonal integral of the model sea surface height (SSH). The top panel is the time series of this mode, normalized to unit variance. The lower panel shows the covariance between the model $\mathrm{SSH}$ at each point and the time series in the upper panel.

regions of volume variability, with a local minimum at $5^{\circ} \mathrm{S}$, and a sign change across $8^{\circ} \mathrm{N}$. These meridional divisions can also be seen in the second multivariate EOF mode computed by Alory and Delcroix [2002] using T/P altimetry and a linear model. Later, we will look at the two-dimensional redistribution. The bottom panel of Figure 7 shows that the dateline is also a reasonable dividing line between the regions of volume variability, and this is consistent with the first multivariate EOF of Alory and Delcroix [2002]. For now, though, we will examine the volume change in each of three geographic boxes: $20^{\circ} \mathrm{S}-5^{\circ} \mathrm{S}, 5^{\circ} \mathrm{S}-8^{\circ} \mathrm{N}$, and $8^{\circ} \mathrm{N}-$ $20^{\circ} \mathrm{N}$, from the western to the eastern boundary, and the redistribution terms between them.

[32] We previously found that the volume variability was dominated by the heat content variability for the $20^{\circ} \mathrm{S}-$ $20^{\circ} \mathrm{N}$ box. This is also the case for the near-equatorial $\left(5^{\circ} \mathrm{S}-8^{\circ} \mathrm{N}\right)$ box (Figure 8$)$, where the heat content term correlates with the total volume change at 0.99 and accounts for $96.9 \%$ of the total variance. The volume drops during events for this box, between 1.5 and $2 \times 10^{12} \mathrm{~m}^{3}$, again correspond to a drop in areally averaged sea level, 6-8 cm, which is comparable to the results of Springer et al. [1990], as shown in their Figure 2. The variability of the heat content in this box is due to a combination of the meridional heat fluxes across $5^{\circ} \mathrm{S}$ and $8^{\circ} \mathrm{N}$ and the vertical heat flux at the sea surface. The salt content variability, the mass content variability, and the total error term are all small. This is not due to any cancellation between the terms such as would be 


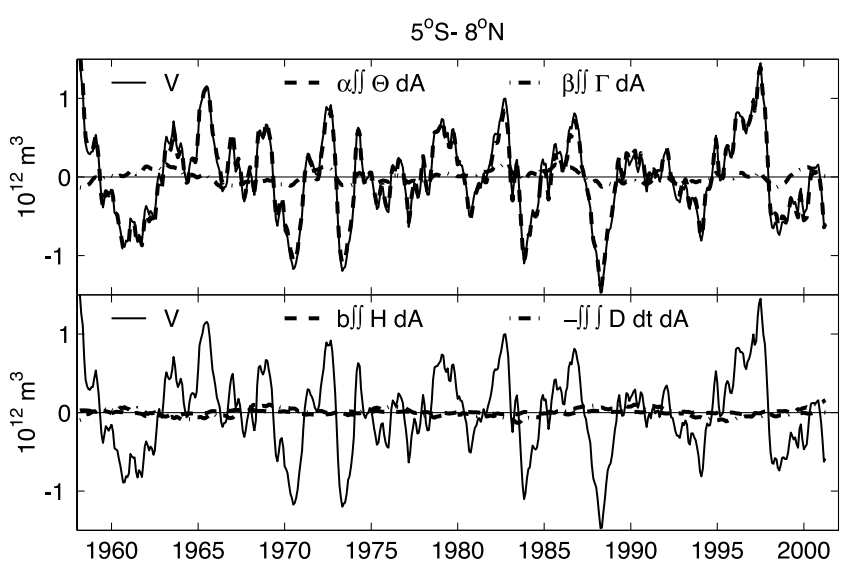

Figure 8. Time series of the model volume variability and its constituents for the $5^{\circ} \mathrm{S}-8^{\circ} \mathrm{N}$ box. The solid line in both panels is the volume variability time series. The dashed line in the top panel, nearly overlying the volume, is the portion of the volume variability, which is accounted for by temperature variability. The dash-dotted line on the top panel is the volume variability due to salinity changes. In the bottom panel, the dashed and dash-dotted lines are the volume variability due to continuity effects (changes in mass within the area) and mismatches from model filtering, respectively.

caused by mass or salt fluxes in the same direction at both $5^{\circ} \mathrm{S}$ and $8^{\circ} \mathrm{N}$, but rather to the small impact of every term. In the northern equatorial box $\left(8^{\circ} \mathrm{N}-20^{\circ} \mathrm{N}\right)$ and the southern equatorial box $\left(20^{\circ} \mathrm{S}-5^{\circ} \mathrm{S}\right)$, the heat content variability once again dominates the volume variability. The correlations are 0.98 for both boxes, and the heat content variability accounts for $90.1 \%$ and $107.1 \%$ of the variance of the volume in the northern and southern boxes, respectively. The meridional fluxes at the northern and southern faces both play an important role, but the importance of the sea surface heat flux term is greatly decreased as compared to the near-equatorial box.

[33] These results are summarized in schematic form in Figure 9, using the scalar indices defined by equation (9). The scalar indices defined by equation (10) give the same spatial pattern. The sea surface heat flux is important only in the near-equatorial region, where it accounts for $61 \%$ of the volume change of the tropical $\left(20^{\circ} \mathrm{S}-20^{\circ} \mathrm{N}\right)$ Pacific as a whole. There are large northward fluxes across both $5^{\circ} \mathrm{S}$ and $8^{\circ} \mathrm{N}$, at $55 \%$ and $122 \%$ of the tropical Pacific volume change. The flux at $5^{\circ} \mathrm{S}$ is the reason that the southern equatorial region varies in the same sense as the nearequatorial, with both losing volume during ENSO events, and the volume gain in the northern equatorial region is caused by the strong flux across $8^{\circ} \mathrm{N}$. These fluxes at $5^{\circ} \mathrm{S}$ and $8^{\circ} \mathrm{N}$ have no impact on the volume variability of the entire tropical Pacific, though; they are simply redistribution terms. The poleward heat fluxes at $20^{\circ} \mathrm{N}$ and $20^{\circ} \mathrm{S}$ are the same as in Figure 6. These results, along with the previously noted reinterpretation of the UHSLC volume curve as the volume from $6^{\circ} \mathrm{S}-6^{\circ} \mathrm{N}$, resolve the apparent conflict between the results of Wyrtki [1985] and those of Miller and Cheney [1990] and Springer et al. [1990]. Although there is indeed a loss of volume from the tropics as a whole, this loss term is significantly smaller than the exchanges between the near-equatorial band and the regions just outside the equatorial band.

\subsection{Zonal and Meridional Redistribution Patterns}

[34] The tropical Pacific was further divided into six boxes, based on the covariance between the model sea level at each grid point and the first EOF mode of the zonally integrated sea level. These boxes are shown in Figure 7. As we have already seen for the tropical Pacific as a whole and the meridional boxes, the volume variability in each of these smaller boxes is again dominated by the heat content variability (Figure 10), with correlations of 0.98 or higher between the total volume change and the contribution of the heat content term. Also, the heat content accounts for between 84 and $110 \%$ of the total variance.

[35] The relative importance of the various terms, scaled as percentages of the total $20^{\circ} \mathrm{S}-20^{\circ} \mathrm{N}$ volume change, are indicated in schematic form in Figure 11. The scalar indices shown are from equation (9), and the indices resulting from equation (10) again show a very similar pattern. The meridional fluxes east and west of the dateline at $20^{\circ} \mathrm{S}$ and $20^{\circ} \mathrm{N}$ are not negligible, but the fluxes west of the dateline are southward while the fluxes east of the dateline are northward, so that the net meridional fluxes, integrated from west to east, are relatively small, as we found in the previous section. The heat flux at the sea surface, while an important factor in the volume change of the tropical Pacific
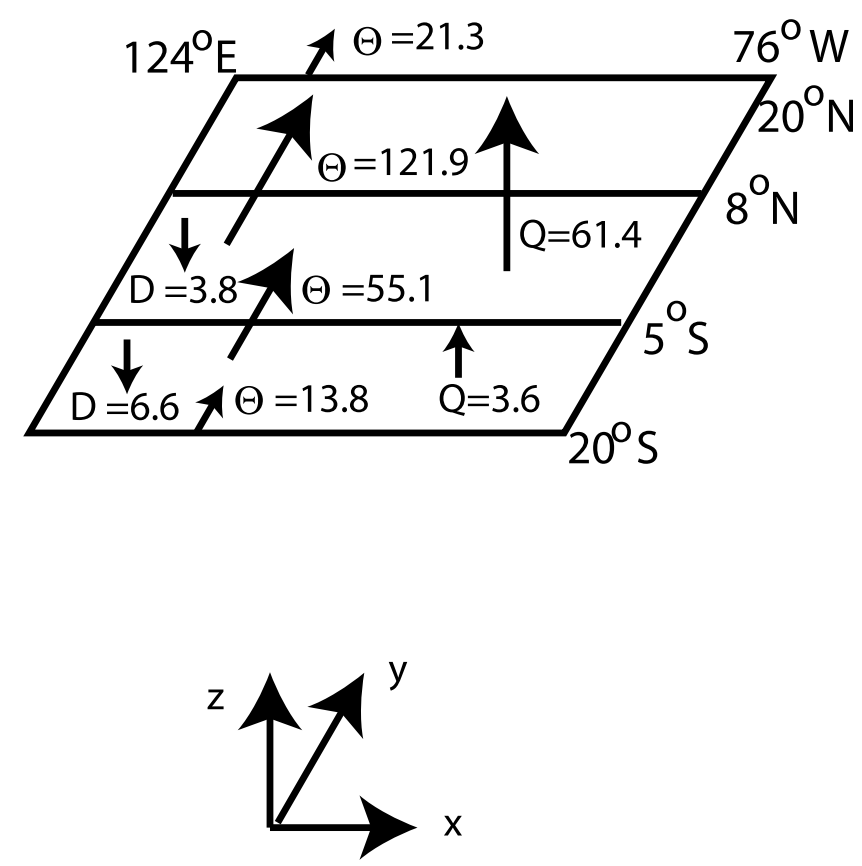

Figure 9. Schematic of volume tendency effects for the $20^{\circ} \mathrm{S}-20^{\circ} \mathrm{N}$ box, subdivided at $5^{\circ} \mathrm{S}$ and $8^{\circ} \mathrm{N}$. The region is shown as an inclined plane. Only terms which are equivalent to at least $3 \%$ of the $20^{\circ} \mathrm{S}-20^{\circ} \mathrm{N}$ volume change are included here. This includes the heat fluxes at the sea surface, Q; heat fluxes across the meridional faces, $\theta$; and mismatches in the temperature equation, D. The number next to the arrow indicates the relative importance of each term. 


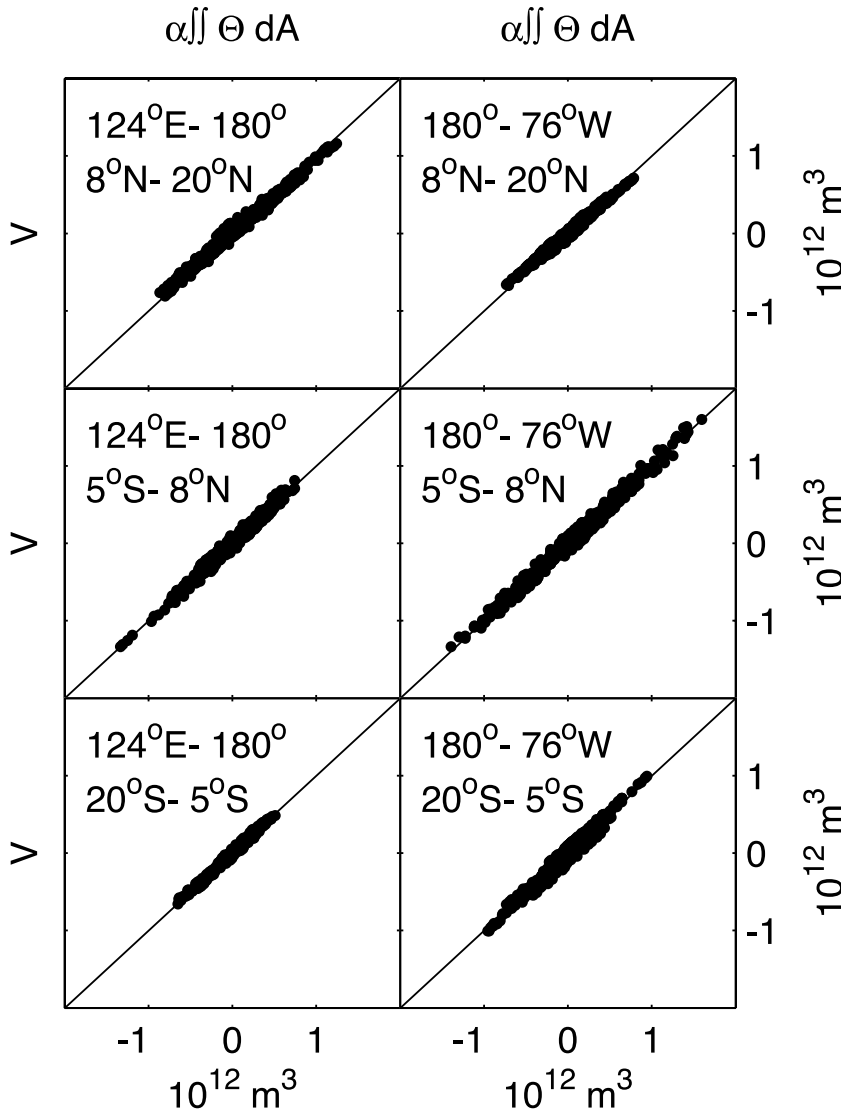

Figure 10. Comparison between the volume variability ( $y$ axis) and the portion accounted for by temperature variations ( $x$ axis) for the six geographic regions defined on the figure. Each panel is simply a scatterplot, and the correlation in all cases (not shown) is greater than 0.98 .

as a whole, is concentrated in the eastern near-equatorial Pacific.

[36] The major signal, not surprisingly, is the strong eastward heat flux across the dateline between $5^{\circ} \mathrm{S}$ and $8^{\circ} \mathrm{N}$, which causes volume loss in the western near-equatorial Pacific and volume increase in the eastern Pacific. In the eastern near-equatorial Pacific, this influx is countered by strong sea surface cooling and by large poleward heat fluxes at $8^{\circ} \mathrm{N}$ and $5^{\circ} \mathrm{S}$. The net effect in this box is volume loss. In the northeastern box, influxes across $8^{\circ} \mathrm{N}$ and the dateline cause a volume increase over the course of an ENSO event. A smaller amount exits at $20^{\circ} \mathrm{N}$, so that the net effect for this box is volume gain. This northward flux at $20^{\circ} \mathrm{N}$ east of the dateline is balanced by a southward heat flux at $20^{\circ} \mathrm{N}$ west of the dateline. The northwestern box also experiences net volume gain as a result of the horizontal heat fluxes.

[37] South of the equator, there is net recirculation of heat over the composite ENSO event. The southward heat flux across $5^{\circ} \mathrm{S}$ east of the dateline and the northward flux across $20^{\circ} \mathrm{S}$ would cause volume gain in the southeastern region, except that a larger amount of heat is fluxed westward across the dateline, creating a net volume loss over ENSO for this box. This westward flux increases the volume in the southwestern box, but this is countered by a southward flux across $20^{\circ} \mathrm{S}$ in this region and a strong northward flux into the western near-equatorial box across $5^{\circ} \mathrm{S}$. The net effect for both the near-equatorial and southern boxes is volume loss over the ENSO period, and the net effect for both of the northern boxes is a roughly equal volume gain.

\subsection{Model Robustness}

[38] As these results depend on the output from a numerical model rather than from observational data, questions of reliability and applicability to the real world should be carefully considered. The results presented thus far are from a single run of the model, which we will refer to as the standard run. In order to test the robustness of our results, we compared multiple model runs in which either the model physics or the forcing was different. First, our standard run was forced by wind from the National Center for Environmental Prediction (NCEP). Broad vertically integrated sea level and sea surface temperature fields have previously been compared between data and model output using a variety of wind-forcing fields for the 1997-1998 ENSO event [Hackert et al., 2001]. Here we do a similar comparison between volume time series computed from model output and those from the T/P altimetric sea surface heights for a variety of wind fields and in a number of geographic areas. In addition, though, one persistent result in every geographic region examined in this study is that the volume variability is dominated by variations in the heat content. These are of course vertically integrated fields, but this dominance of the heat content suggests that the mixed layer dynamics may be important in the volume variability. We
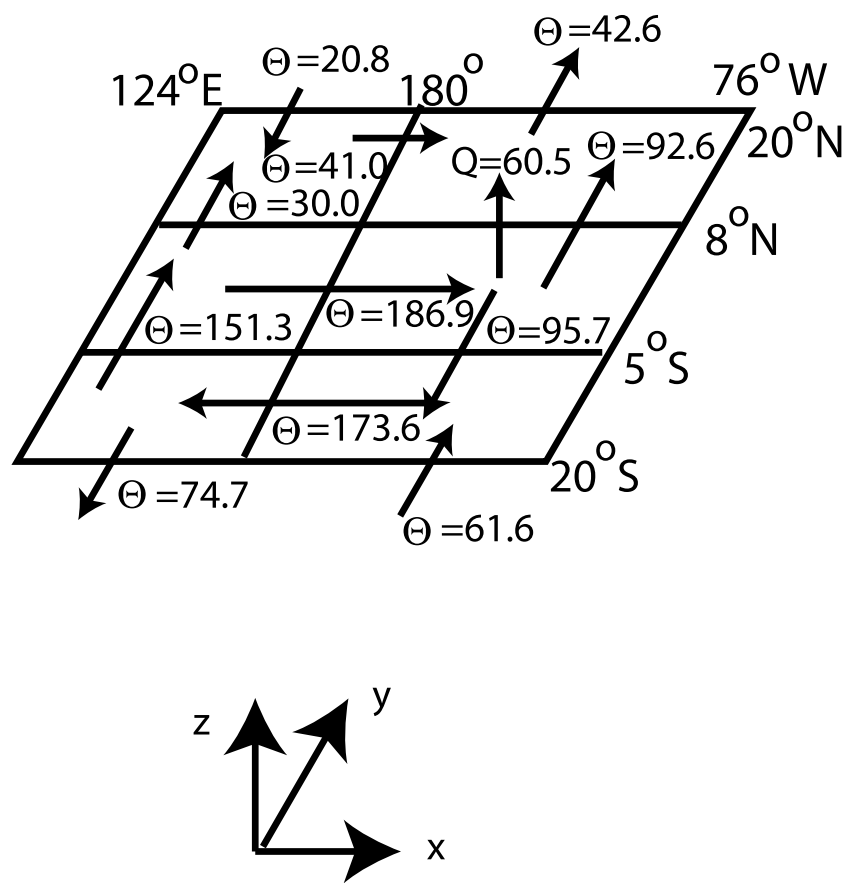

Figure 11. Schematic of volume tendency effects for the $20^{\circ} \mathrm{S}-20^{\circ} \mathrm{N}$ box, subdivided at $180^{\circ}, 5^{\circ} \mathrm{S}$, and $8^{\circ} \mathrm{N}$. The region is shown as an inclined plane. Only terms which are equivalent to at least $10 \%$ of the $20^{\circ} \mathrm{S}-20^{\circ} \mathrm{N}$ volume change are included here. This includes the heat flux at the sea surface, Q, and heat fluxes across the zonal and meridional faces, $\theta$. The number next to the arrow indicates the relative importance of each term. 
therefore completed a series of test runs in which the mixed layer dynamics of the model were altered in order to further to test the robustness of our results.

[39] To test the robustness to the wind-forcing fields, five relatively short model runs were done using different wind fields. These fields were from the European Centre for Medium-Range Weather Forecasts (ECMWF), the European Remote Sensing Satellites (ERS), Florida State University (FSU), NCEP, and the Special Sensor Microwave Imager (SSM/I). The variances of the resulting volume time series were in every case comparable to the volume computed from the $\mathrm{T} / \mathrm{P}$ altimetric data. Correlations with $\mathrm{T} / \mathrm{P}$ were greater than 0.61 for the $20^{\circ} \mathrm{S}-20^{\circ} \mathrm{N}$ region for every wind field, and greater than 0.85 for the $5^{\circ} \mathrm{S}-5^{\circ} \mathrm{N}$ region.

[40] Several longer runs were also completed to test the sensitivity of the volume variability to different mixed layer dynamics. The standard run used the Chen et al. [1994] hybrid mixing scheme. This scheme has a tunable parameter that controls the degree of wind stirring, which is set to 1.25 in the standard run. Runs were completed with this parameter halved (0.6) and doubled (2.5), along with an additional run with a fixed mixed layer depth of $50 \mathrm{~m}$. The volume time series were nearly indistinguishable between these runs for the latitude ranges of $25^{\circ} \mathrm{S}-15^{\circ} \mathrm{S}, 15^{\circ} \mathrm{S}-5^{\circ} \mathrm{S}, 5^{\circ} \mathrm{S}-5^{\circ} \mathrm{N}$, $5^{\circ} \mathrm{N}-15^{\circ} \mathrm{N}$, and $15^{\circ} \mathrm{N}-25^{\circ} \mathrm{N}$. All of these runs agreed well with the $\mathrm{T} / \mathrm{P}$ volume time series during the time period when T/P data are available.

[41] In addition, all of the analyses of the relative importance of the terms to the volume change and redistribution, which were described above, were repeated for the model runs with different mixed layer dynamics. The resulting spatial patterns were nearly indistinguishable from Figure 11. We conclude, therefore, that the largescale patterns of volume change and redistribution, at least in terms of the vertically integrated quantities examined in this paper, are robust to changes in wind-forcing and mixed layer dynamics of the numerical model.

\section{Summary and Conclusions}

[42] Volume variability within any geographic region can in theory result from changes in heat, salt, or mass content, as in equation (7). We find, however, that the volume variability is dominated by the heat content variability in every geographic box examined in this study. Using ENSO composite time series, we also conclude that volume is indeed lost from the tropical Pacific as a whole $\left(20^{\circ} \mathrm{S}-\right.$ $20^{\circ} \mathrm{N}$ ) over the course of an ENSO event, as suggested by Wyrtki [1985]. This volume loss, however, is relatively small compared to the redistribution in both the zonal and meridional directions within the tropics, which agrees with the findings of Miller and Cheney [1990] and Springer et al. [1990]. Our findings therefore reconcile the results of Miller and Cheney [1990] and Springer et al. [1990] with the earlier results of Wyrtki [1985]. The results of this paper are based on the output of a numerical model, but the volume time series agree well with volume from an areal integration the T/P altimetric sea surface heights, and our results are robust to variations in the wind-forcing and in the mixed layer dynamics of the model, even if a simplistic 50-m-thick fixed mixed layer is applied. In future work, we will focus on further analysis of the largest signal and the redistribu- tion of heat content within the tropical Pacific and we will examine the three-dimensional pathways that lead to these volume changes.

[43] Acknowledgments. The work was supported by NASA and the Jet Propulsion Laboratory as part of the TOPEX Altimeter Research in Ocean Circulation and the JASON-1 project. C. Holland was partially supported by a NASA Earth System Science Fellowship. We thank R. Murtugudde, A. Busalacchi, R. Weisberg, M. Luther, and F. MullerKarger for many helpful discussions.

\section{References}

Alory, G., and T. Delcroix, Interannual sea level changes and associated mass transports in the tropical Pacific from TOPEX/Poseidon data and linear model results (1964-1999), J. Geophys. Res., 107(C10), 3153, doi:10.1029/2001JC001067, 2002.

Battisti, D. S., On the role of off-equatorial oceanic Rossby waves during ENSO, J. Phys. Oceanogr., 19, 551-559, 1989.

Battisti, D. S., and A. C. Hirst, Interannual variability in a tropical atmosphere-ocean model: Influence of the basic state, ocean geometry and nonlinearity, J. Atmos. Sci., 46, 1687-1712, 1989.

Bjerknes, J., Atmospheric teleconnections from the equatorial Pacific, Mon. Weather Rev., 97, 163-172, 1969.

Cane, M. A., and S. E. Zebiak, A theory for El Niño and the Southern Oscillation, Science, 228, 1084-1087, 1985.

Chen, D., L. M. Rothstein, and A. J. Busalacchi, A hybrid vertical mixing scheme and its application to tropical ocean models, J. Phys. Oceanogr., 24, 2156-2179, 1994.

Gent, P. G., and M. A. Cane, A reduced gravity, primitive equation model of the upper equatorial ocean, J. Comput. Phys., 81, 444-480, 1989.

Gill, A. E., Some simple solutions for heat-induced tropical circulation, Q. J. R. Meteorol. Soc., 106, 447-462, 1980.

Hackert, E., A. J. Busalacchi, and R. Murtugudde, A wind comparison study using an ocean general circulation model for the 1997-1998 El Niño, J. Geophys. Res., 106, 2345-2362, 2001.

Hasegawa, T., and K. Hanawa, Heat content variability related to ENSO events in the Pacific, J. Phys. Oceanogr., 33, 407-421, 2003.

Jin, F.-F., An equatorial ocean recharge paradigm for ENSO: I. Conceptual model, J. Atmos. Sci., 54, 811-829, 1997a

Jin, F.-F., An equatorial ocean recharge paradigm for ENSO: I. A stripped down coupled model, J. Atmos. Sci., 54, 830-847, $1997 \mathrm{~b}$.

Meinen, C. S., and M. J. McPhaden, Observations of warm water volume changes in the equatorial Pacific and their relationship to El Niño and La Niña, J. Clim., 13, 3551-3559, 2000.

Miller, L., and R. Cheney, Large-scale meridional transport in the tropical Pacific Ocean during the 1986-1987 El Niño from Geosat, J. Geophys. Res., 95, 17,905-17,919, 1990.

Mitchum, G. T., Trade-wind fluctuations associated with El Niño-Southern Oscillation events, J. Geophys. Res., 92, 9464-9468, 1987.

Murtugudde, R., and A. J. Busalacchi, Salinity effects in a tropical ocean model, J. Geophys. Res., 103, 3283-3300, 1998.

Murtugudde, R., R. Seager, and A. Busalacchi, Simulation of the tropical oceans with an ocean GCM coupled to an atmospheric mixed-layer model, J. Clim., 9, 1795-1815, 1996.

Neelin, J. D., A hybrid coupled general circulation model for El Niño studies, J. Atmos. Sci., 47, 674-693, 1990.

Perigaud, C., S. E. Zebiak, F. Melin, J.-P. Boulanger, and B. Dewitte, On the role of meridional wind anomalies in a coupled model of ENSO, J. Clim., 10, 761-773, 1997.

Perigaud, C., F. Melin, and C. Cassou, ENSO simulated by intermediate coupled models and evaluated with observations over 1970-98: I. Role of the off-equatorial variability, J. Clim., 13, 1605-1634, 2000.

Picaut, J., M. Ioualalen, C. Menkes, T. Delcroix, and M. J. McPhaden, Mechanism of the zonal displacements of the Pacific warm pool: Implications for ENSO, Science, 274, 1486-1489, 1996.

Picaut, J., F. Masia, and Y. du Penhoat, An advective-reflective conceptual model for the oscillatory nature of the ENSO, Science, 277, 663-666, 1997.

Schopf, P. S., and D. E. Harrison, On equatorial waves and El Niño: I. Influence of initial states on wave-induced currents and warming, J. Phys. Oceanogr., 13, 936-948, 1983.

Schopf, P. S., and M. J. Suarez, Vacillations in a coupled ocean-atmosphere model, J. Atmos. Sci., 45, 549-566, 1988.

Schopf, P. S., and M. J. Suarez, Ocean wave dynamics and the time scale of ENSO, J. Phys. Oceanogr., 20, 629-645, 1990.

Seager, R., and R. Murtugudde, Ocean dynamics, thermocline adjustment, and regulation of tropical SST, J. Clim., 10, 521-534, 1995. 
Shapiro, R., Smoothing, filtering and boundary effects, Rev. Geophys., 8 , 359-387, 1970.

Springer, S. R., M. J. McPhaden, and A. J. Busalacchi, Oceanic heat content variability in the tropical Pacific during the 1982/1983 El Niño, J. Geophys. Res., 95, 22,089-22,101, 1990.

Wang, C., A unified oscillator model for the El Niño-Southern Oscillation, J. Clim., 14, 98-115, 2001.

Wang, C., R. H. Weisberg, and J. I. Virmani, Western pacific interannual variability associated with the El Niño-Southern Oscillation, J. Geophys. Res., 104, 5131-5149, 1999.

Weisberg, R. H., and C. Wang, A western Pacific oscillator paradigm for the El Niño-Southern Oscillation, Geophys. Res. Lett., 24, 779-782, 1997.

Wyrtki, K., El Niño: The dynamics response of the equatorial Pacific Ocean to atmospheric forcing, J. Phys. Oceanogr., 5, 572-584, 1975.
Wyrtki, K., Water displacements in the Pacific and the genesis of El Niño cycles, J. Geophys. Res., 90, 7129-7132, 1985.

Wyrtki, K., and G. Mitchum, Interannual differences of Geosat altimeter heights and sea level: The importance of datum, J. Geophys. Res., 95, 2969-2975, 1990.

Zebiak, S. E., and M. A. Cane, A model for El Niño-Southern Oscillation, Mon. Weather Rev, 115, 2262-2278, 1987.

Zimbelman, D. F., and A. J. Busalacchi, The wet tropospheric range correction: Product intercomparisons and the simulated effect for tropical Pacific altimeter retrievals, J. Geophys. Res., 95, 2899-2922, 1990.

C. L. Holland and G. T. Mitchum, College of Marine Science, University of South Florida, 140 Seventh Ave. South, St. Petersburg, FL 33701, USA. (cholland@marine.usf.edu; mitchum@marine.usf.edu) 